\title{
Effect of Composition and Mass Ratio on the Catalytic Wet Air Oxidation Catalyst $\mathrm{Cu}-\mathrm{Fe}-\mathrm{La} / \mathrm{FSC}$
}

\author{
Chao WU, Jianru TAN ${ }^{\mathrm{b}}$, Haimei $\mathrm{HUANG}^{\mathrm{c}}$ and Senlin $\mathrm{CHEN}^{\mathrm{d}}$ \\ School of Chemical and Environmental Engineering, Hanshan Normal University, Chaozhou 521041, \\ China.

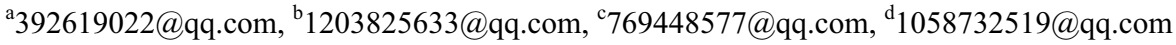

\begin{abstract}
The catalytic wet air oxidation (CWAO) technology is used for the treatment of the simulated printing and dyeing wastewater and also for investigating the catalyst performance indicators such as catalyst activity and stability. The catalyst activity is mainly reflected from the water decolorization and $\mathrm{COD}_{\mathrm{Cr}}$ removal rates, and the stability of the catalyst is mainly reflected by the quantity of metal dissolution. The experimental results showed that the prepared $\mathrm{Cu}-\mathrm{Fe}-\mathrm{La} / \mathrm{FSC}$ catalyst with a 1:1:2 ratio of $\mathrm{Cu}-\mathrm{Fe}-\mathrm{La}$ by the impregnation method exhibited good activity for the treatment of the simulated printing and dyeing wastewater by the CWAO method, and the decolorization and $\mathrm{COD}_{\mathrm{Cr}}$ removal rates using this catalyst were $98.7 \%$ and $78.6 \%$, respectively, with a higher catalytic activity, lower concentration of metal dissolution, and good stability.

Keywords: $\mathrm{Cu}-\mathrm{Fe}-\mathrm{La} / \mathrm{FSC}$; CWAO; Printing and dyeing wastewater; Decolorization rate; $\mathrm{COD}_{\mathrm{Cr}}$ removal rate
\end{abstract}

\section{Introduction}

The printing and dyeing wastewater at higher concentrations, big chromaticity, complexly composition and difficulty to biodegrade is a big problem in the industrial wastewater treatment, and it is also a very interesting issue to study [1]. The core technology of the catalytic wet air oxidation (CWAO) is the selection of catalyst, and the catalyst activity depends on the types of catalyst and the ratio between the types of catalyst and cocatalyst [2]. The CWAO process was used for the treatment of the simulated dyeing and printing wastewater by the immersion type catalysts, using active $\mathrm{Cu}$ and $\mathrm{Fe}$ as the cost-effective metals [3], and at the same time, La cocatalyst with special physiochemical properties was added [4]. In this study, we developed a treatment of printing and dyeing wastewater with a high $\mathrm{COD}_{\mathrm{Cr}}$ removal rate of the catalyst, and this study could provide a scientific basis for the printing and dyeing wastewater CWAO process. Moreover, the preparation of transition metal and rare earth catalysts, and their CWAO performance were investigated in this study $[5]$. 


\section{Materials and Methods}

\subsection{Samples and materials}

Methyl orange simulated printing and dyeing wastewater $\left(\mathrm{COD}_{\mathrm{Cr}}: 2,000 \mathrm{mg} / \mathrm{L}\right)$, copper nitrate, nitric acid, iron, cerium nitrate, lanthanum nitrate, methyl orange, potassium dichromate, ammonium ferrous sulfate, and $98 \%$ sulfuric acid were purchased from Sigma-Aldrich (St. Louis, USA) and were of analytical grades.

\subsection{Equipment and instruments}

GS type permanent magnet rotating stirred autoclave (Material 316L, $\mathrm{Cr}_{18} \mathrm{Ni}_{12} \mathrm{Mo}_{2-3}$ ), the detection of $\mathrm{COD}_{\mathrm{Cr}}$ all-glass distillation unit, atomic absorption spectrometer (AAS), spectrophotometer, $\mathrm{pH}$ meter, electronic precision balance, and muffle furnace were used.

\subsection{Analysis method}

Chemical oxygen demand $\left(\mathrm{COD}_{\mathrm{Cr}}\right)$ was determined by the $\mathrm{GB}$ dichromate method. Turbidity was determined by spectrophotometric method.

Decolorization rate $\eta=\frac{A 0-A}{A 0} \times 100 \%$.

where A0: the absorbance of raw water and A is the absorbance of water after the processing

\subsection{Preparation of catalysts}

The load type multicomponent catalysts were prepared by the impregnation method. To ensure full immersion, the excessive impregnation method was used, and the required amounts of the active substances were accurately weighed and dissolved in a certain ratio of distilled water and the impregnation liquid by mass fraction. The FSC dipping was placed in the corresponding impregnation liquid, and after a period of impregnation and drying, the resulting materials were roasted at $450{ }^{\circ} \mathrm{C}$ in a muffle furnace for $3 \mathrm{~h}$ to afford the corresponding catalysts.

\section{Results and Discussion}

\subsection{Methyl orange blank experiment}

The effect of catalysts was investigated by first performing blank experiment using methyl orange to ensure whether it had an impact on the decolorization rate of water and $\mathrm{COD}_{\mathrm{Cr}}$ after adding the catalyst, and the experimental data are shown in Table 1.

Fig. 1 shows that the $\mathrm{pH}$ of water first decreases and then increases. The initial amounts of organic matter rapidly decomposed into small molecular organic components. At higher temperatures, $\mathrm{pH}$ first decreased, and later the oxidation of small organic molecules led to further oxidative decomposition, reducing the acidity of the solution, thereby increasing the water $\mathrm{pH}$.After $90 \mathrm{~min}$ of the reaction, at equilibrium, the decolorization and $\mathrm{COD}_{\mathrm{Cr}}$ removal rates of methyl orange blank liquid were $78.8 \%$ and $56.8 \%$, respectively. 
Table 1 Methyl Orange Blank Experiment

\begin{tabular}{|c|c|c|c|c|c|}
\hline Sampling time $(\mathrm{min})$ & 10 & 20 & 40 & 60 & 90 \\
\hline Dilution ration & 100 & 100 & 50 & 50 & 50 \\
\hline Decoloring rate $\eta(\%)$ & 39.5 & 53.4 & 71.2 & 76 & 78.8 \\
\hline $\begin{array}{c}\text { Removal rate of } \mathrm{COD}_{\mathrm{Cr}} \\
\eta(\%)\end{array}$ & 206 & 484 & 496 & 642 & 1136 \\
\hline $\mathrm{pH}$ & 5.68 & 4.94 & 5.82 & 6.59 & 7.3 \\
\hline
\end{tabular}

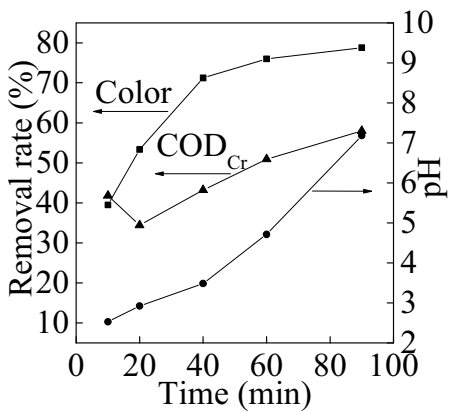

Fig.1 Methyl orange blank experiment

\subsection{Experimental results and analysis of the catalysts}

\subsubsection{Choice of transition metal catalysts}

The catalyst activity and stability largely depend on its composition. At first $\mathrm{Fe}, \mathrm{Cu}$, and composite $\mathrm{Cu}-\mathrm{Fe}$ catalysts were chosen for comparison. The experimental data are shown in Table 2.

As shown in Table 2, after adding the catalyst, the decolorization and $\mathrm{COD}_{\mathrm{Cr}}$ removal rates increased significantly, as shown in Fig. 2(a) for the treatment of the simulation of the printing and dyeing wastewater. The decolorization rate of the catalyst containing $\mathrm{Cu}$ was better than that containing only Fe catalyst. After $60 \mathrm{~min}$, the decolorization rate of $\mathrm{Cu}-\mathrm{Fe} / \mathrm{FSC}$ catalyst was same as that of $\mathrm{Cu} / \mathrm{FSC}$ catalyst. Fig. 2(b) shows that the catalysts containing only $\mathrm{Fe}$ did not show significant $\mathrm{COD}_{\mathrm{Cr}}$ removal rate, and the $\mathrm{COD}_{\mathrm{Cr}}$ removal rates of the catalysts with only $\mathrm{Cu}$ were significantly higher than that of the catalysts with $\mathrm{Fe}$. The $\mathrm{COD}_{\mathrm{Cr}}$ removal rate of the catalyst with only $\mathrm{Cu}$ was better than that of the catalyst with $\mathrm{Cu}-\mathrm{Fe}$. In general, in the first $40 \mathrm{~min}$ the reaction rate increased; after $60 \mathrm{~min}$, the reaction rate decreased slowly; after $90 \mathrm{~min}$, it reached to equilibrium state and the decolorization rate ( $\eta$ ) was as high as $99.8 \%$, and the $\operatorname{COD}_{\mathrm{Cr}}$ removal rate was $91.2 \%$ with a high catalyst performance.

The atomic absorption spectroscopy (AAS) showed that higher the impregnation liquid concentration, greater the effluent concentration, because of metal dissolution, which could cause secondary pollution to the environment. Therefore, the $\mathrm{Cu}-\mathrm{Fe} / \mathrm{FSC}$ catalyst was chosen based on the catalytic activity, cost-effectiveness, environmental protection, and relatively higher decolorization and $\mathrm{COD}_{\mathrm{Cr}}$ removal rates. 
Table 2 Transition Metal Catalyst For Experimental Data Processing

\begin{tabular}{|c|c|c|c|c|}
\hline & Sampling time $(\mathrm{min})$ & $\mathrm{Fe} / \mathrm{FSC}$ & $\mathrm{Cu}-\mathrm{Fe} / \mathrm{FSC}$ & $\mathrm{Cu} / \mathrm{FSC}$ \\
\hline \multirow{4}{*}{$\begin{array}{c}\text { Decoloring rate } \\
\eta(\%)\end{array}$} & 10 & 23.1 & 52.2 & 63.3 \\
\cline { 2 - 5 } & 20 & 28.2 & 81.3 & 81 \\
\cline { 2 - 5 } & 40 & 48.4 & 97.4 & 97.3 \\
\cline { 2 - 5 } & 60 & 61.9 & 99.3 & 99.5 \\
\cline { 2 - 5 } & 90 & 75 & 99.5 & 99.7 \\
\cline { 2 - 5 } & 10 & 34.7 & 37.2 & 50 \\
\cline { 2 - 5 } $\begin{array}{c}\text { Removal rate of } \\
\text { COD }_{\mathrm{Cr}} \eta(\%)\end{array}$ & 20 & 36.5 & 48.3 & 75.5 \\
\cline { 2 - 5 } & 40 & 41.3 & 66.7 & 82.8 \\
\cline { 2 - 5 } & 90 & 48.3 & 80.1 & 91.2 \\
\hline
\end{tabular}
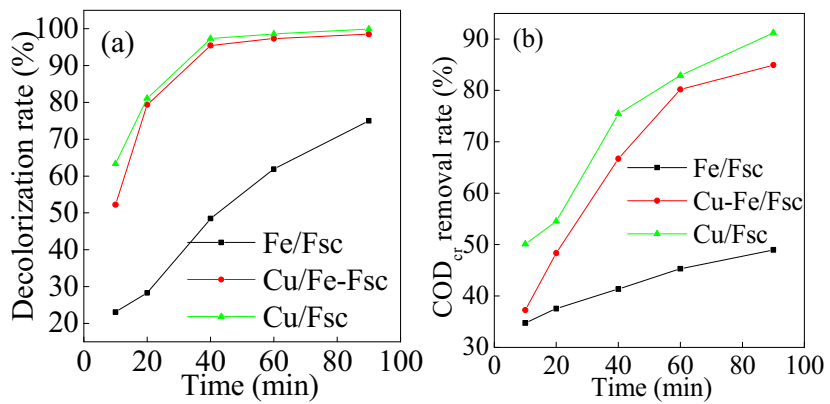

Fig. 2 The curve of the transition metal catalyst performance with time

\subsubsection{Choice of rare earth elements in catalytic system}

After determining the composition of the $\mathrm{Cu}-\mathrm{Fe}-\mathrm{FSC}$ catalyst, to increase the stability of the catalyst, the rare earth elements $\mathrm{Ce}$ and $\mathrm{La}$ were added to the catalyst, and their compositions were determined. The experimental data are listed in Table 3.

Fig. 3(a) shows that the addition of Ce or La to the catalyst increased the decolorization rate with increasing reaction time, and the catalyst with La exhibited obviously better decolorization rate than the catalyst with $\mathrm{Ce}$, and with both $\mathrm{Ce}$ and $\mathrm{La}$, the catalyst decolorization effect was between the two separate catalytic effects.

The change in the $\mathrm{COD}_{\mathrm{Cr}}$ removal rate had a similar trend to that of the decolorization rate. The $\mathrm{Cu}-\mathrm{Fe}-\mathrm{La} / \mathrm{FSC}$ catalyst obviously had significantly better effect on the simulated printing and dyeing wastewater treatment than the other two types of catalysts and was measured by AAS. The $\mathrm{Cu}-\mathrm{Fe}-\mathrm{La} / \mathrm{FSC}$ catalyst was chosen, because the dissolution of metal was not significant, thereby it poses less pollution to the environment.

Table 3 Rare Earth Metal Catalysts Experimental Data Processing

\begin{tabular}{|c|c|c|c|c|}
\hline & $\begin{array}{c}\text { Sampling } \\
\text { time(min) }\end{array}$ & $\mathrm{Cu}-\mathrm{Fe}-\mathrm{Ce}=1: 1: 2$ & $\mathrm{Cu}-\mathrm{Fe}-\mathrm{La}=1: 1: 2$ & $\mathrm{Cu}-\mathrm{Fe}-\mathrm{Ce}-\mathrm{La}=1: 1: 1: 1$ \\
\hline \multirow{4}{*}{$\begin{array}{c}\text { Decoloring } \\
\text { rateๆ(\%) }\end{array}$} & 10 & 17.5 & 35 & 21.7 \\
\cline { 2 - 5 } & 20 & 44.3 & 54.9 & 46.4 \\
\cline { 2 - 5 } & 40 & 74.9 & 81.7 & 77.2 \\
\cline { 2 - 5 } & 60 & 85.7 & 97.4 & 91.3 \\
\hline Removal rate of & 10 & 91.3 & 98.9 & 68.9 \\
\hline
\end{tabular}




\begin{tabular}{|c|c|c|c|c|}
\hline $\operatorname{COD}_{\mathrm{Cr}} \eta(\%)$ & 20 & 710 & 802 & 770 \\
\cline { 2 - 5 } & 40 & 974 & 1232 & 1086 \\
\cline { 2 - 5 } & 60 & 1104 & 1474 & 1276 \\
\cline { 2 - 5 } & 90 & 1190 & 1566 & 1536 \\
\hline
\end{tabular}
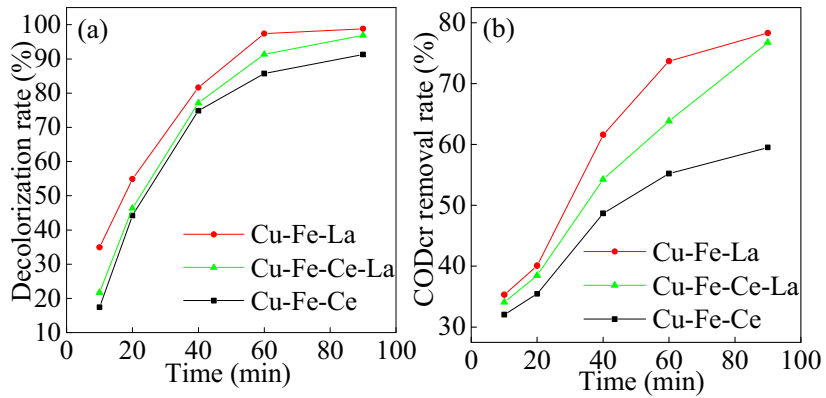

Fig.3 Rare earth catalyst performance and the curve of time

\subsubsection{Ce quality formula of catalytic agent selection}

After determining the concentrations of three types of metals $\mathrm{Cu}, \mathrm{Fe}$, and $\mathrm{La}$, different proportions of La element were chosen for the optimization of the catalysts for better catalytic activity, and the experimental data are listed in Table 4.

Fig. 4 shows that when the proportion of $\mathrm{La}$ in the catalyst is smaller, the decolorization and $\mathrm{COD}_{\mathrm{Cr}}$ removal rates of the catalyst are higher. Different proportions of $(\mathrm{Cu}-\mathrm{Fe}): \mathrm{La}$ were used for the optimization of the performance of the catalysts, and the order of catalytic effects of the catalysts with different proportions of $(\mathrm{Cu}-\mathrm{Fe}): \mathrm{La}$ is as follows: $3: 1>2: 1>$ $1: 1>1: 2>1: 3$. A 1:1:2 ratio of $\mathrm{Cu}-\mathrm{Fe}-\mathrm{La}$ was selected, because of a better catalytic effect and high stability. The decolorization and $\mathrm{COD}_{\mathrm{Cr}}$ removal rates of the catalyst with 1:1:2 ratio of $\mathrm{Cu}-\mathrm{Fe}-\mathrm{La}$ were $98.7 \%$ and $78.6 \%$, respectively, together with a lower metal dissolution rate, thus exhibiting better catalytic activity, cost-effectiveness, and environmental protection. Therefore, a 1:1:2 ratio of $\mathrm{Cu}-\mathrm{Fe}-\mathrm{La}$ metals in the catalyst was used for the subsequent experiments of the simulated dyeing and printing wastewater treatment.

Table 4 The La In Different Proportions Catalyst

\begin{tabular}{|c|c|c|c|c|c|c|}
\hline & $\begin{array}{c}\text { Sampling } \\
\text { time(min) }\end{array}$ & $(\mathrm{Cu}-\mathrm{Fe})-\mathrm{La}$ & $(\mathrm{Cu}-\mathrm{Fe})-\mathrm{La}$ & $(\mathrm{Cu}-\mathrm{Fe})-\mathrm{La}$ & $(\mathrm{Cu}-\mathrm{Fe})-\mathrm{La}$ & $(\mathrm{Cu}-\mathrm{Fe})-\mathrm{La}$ \\
\cline { 2 - 7 } & 10 & 33.7 & $2: 1$ & $1: 1$ & $1: 2$ & $1: 3$ \\
\cline { 2 - 7 } & 20 & 52.6 & 51.8 & 32.5 & 30.7 & 28.4 \\
\cline { 2 - 7 } & 40 & 87.2 & 84.8 & 61.5 & 57.4 & 54.4 \\
\cline { 2 - 7 } & 60 & 97.7 & 96.5 & 94.6 & 85.9 & 82.4 \\
\cline { 2 - 7 } $\begin{array}{c}\text { Decoloring } \\
\text { raten(\%) }\end{array}$ & 90 & 99.4 & 99.2 & 98.7 & 95.7 & 94.1 \\
\cline { 2 - 7 } & 10 & 814 & 794 & 766 & 722 & 702 \\
\hline \multirow{4}{*}{$\begin{array}{c}\text { Removal } \\
\text { rate of }\end{array}$} & 20 & 874 & 842 & 826 & 788 & 768 \\
\cline { 2 - 7 } & 40 & 1218 & 1166 & 1052 & 932 & 884 \\
\cline { 2 - 7 } & 60 & 1562 & 1438 & 1270 & 1176 & 1126 \\
\cline { 2 - 7 } & 90 & 1760 & 1568 & 1488 & 1360 & 1310 \\
\hline
\end{tabular}



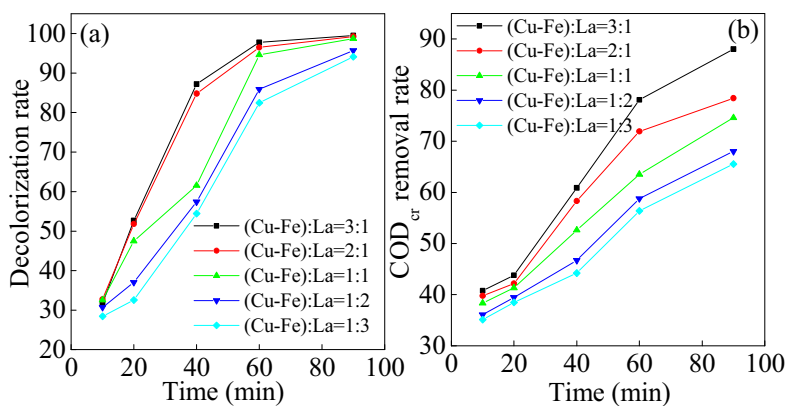

Fig. 4. Different proportion ( $\mathrm{Cu}-\mathrm{Fe})$-La catalyst performance and the curve of the time

\section{SEM And TEM}

The SEM images of the impregnated catalyst after the roasting are shown in Figs. 5a-5c, indicating that the carrier FSC at $450{ }^{\circ} \mathrm{C}$ after dipping, and calcination exhibited a uniform distribution, porous structure, and the catalyst active component is $\sim 500 \mu \mathrm{m}$ particle aggregates covering on the surface of the carrier; therefore, the carrier offers a porous surface structure. Comparison of the SEM images before and after the adsorption shows that the surface has a small amount of material, and the material structure slightly changed but the stability was good. The TEM image of the catalyst FSC shows the catalyst's particles in the diameter range 10-30 $\mathrm{nm}$ with a higher dispersion and less load (Fig. 5(d)).
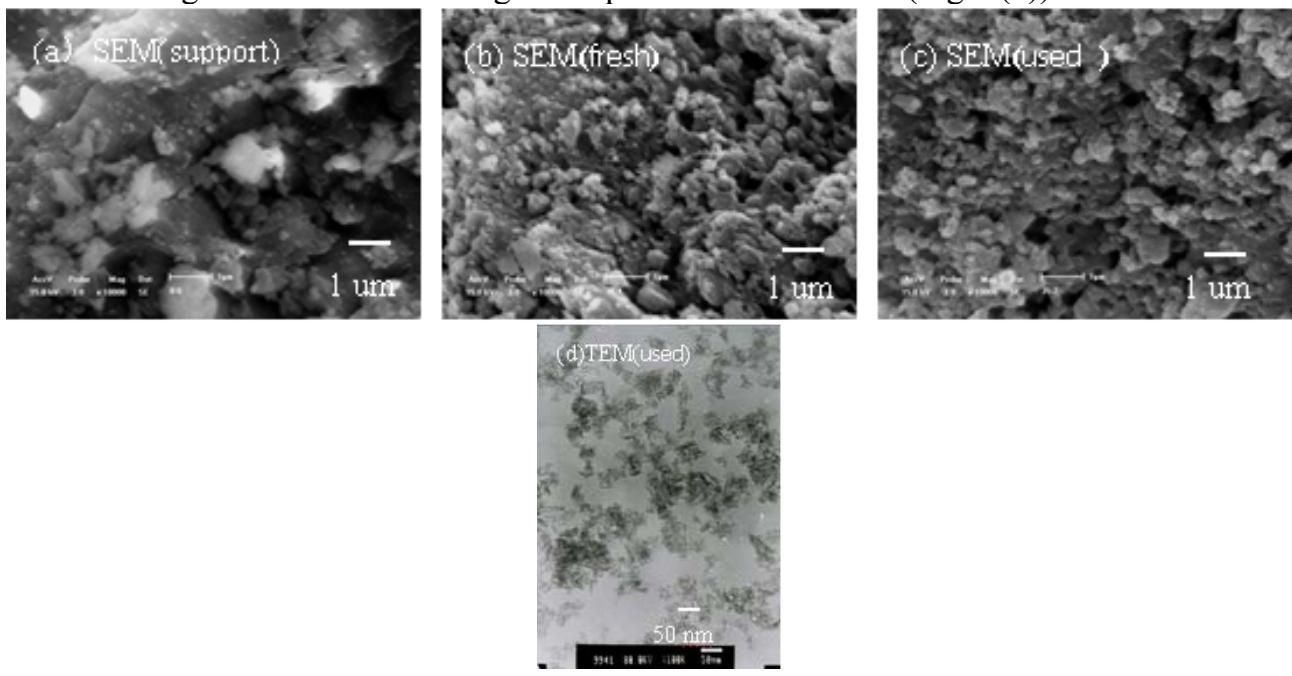

Fig. 5 SEM and TEM photos of fresh and used Cu-Fe-La/FSC

\section{Conclusions}

The single factor variable method was used to determine the metal concentration. According to the proportion of $\mathrm{La}$ in the catalysts, five types of catalysts were tested for $(\mathrm{Cu}-\mathrm{Fe}): \mathrm{La}$ ratios of $3: 1,2: 1,1: 1,1: 2$, and 1:3. With increasing proportions of $\mathrm{La}$, the catalysts exhibited a poor decolorization effect, and the $\mathrm{COD}_{\mathrm{Cr}}$ removal effect was not significant; however, less metal was dissolved. In conclusion, a 1:1 ratio of $(\mathrm{Cu}-\mathrm{Fe}): \mathrm{La}$ was selected as it exhibited a remarkable decolorization effect, $\mathrm{COD}_{\mathrm{Cr}}$ removal rate, and lower dissolubility of metal. As the reaction reached to the equilibrium state, the water 
decolorization rate increased gradually, the $\mathrm{COD}_{\mathrm{Cr}}$ removal rate also increased, and the $\mathrm{pH}$ decreased slowly. A 1:1 ratio of $(\mathrm{Cu}, \mathrm{Fe}): \mathrm{La}$ was used for the treatment of the simulated printing and dyeing wastewater, and the decolorization and $\mathrm{COD}_{\mathrm{Cr}}$ removal rates were $98.7 \%$ and $78.6 \%$, respectively, with a higher catalytic activity, less metal dissolution, and good stability.

\section{Acknowledgments}

This work was supported by the college professor starting project in Hanshan Normal University (QD20140615) and the National Natural Science Foundation of China (51574146).

\section{References}

1. H.F. Wu, S.H. Wang, Impacts of operating parameters on oxidation-reduction potential and pretreatment efficacy in the pretreatment of printing and dyeing wastewater by Fenton process J. Hazard. Mater. 243 (2012) 86-94.

2. S.A. Messele, O.S.G.P. Soares, J.J.M. Órfão, et al. Zero-valent iron supported on nitrogen-containing activated carbon for catalytic wet peroxide oxidation of phenol, Appl. Catal. B 154 (2014) 329-338.

3. G.R. Helz, B.E. Erickson, T.P. Vorlicek, Stabilities of thiomolybdate complexes of iron; implications for retention of essential trace elements $(\mathrm{Fe}, \mathrm{Cu}, \mathrm{Mo})$ in sulfidic waters, Metallomics, 6 (2014) 1131-1140.

4. G.Nandi, H.M. Titi, R.Thakuria, Solvent Dependent Formation of Metallogels and Single-Crystal MOFs by La(III) and Ce(III) Connectors and 3,5-Pyridinedicarboxylate, Cryst. Growth Des. 14 (2014) 2714-2719.

5. M.S. Refat, F.M. Al-Azab, H.M.A. Al-Maydama, et al: Preparation, spectroscopic and thermal characterization of new $\mathrm{La}(\mathrm{III}), \mathrm{Ce}(\mathrm{III}), \mathrm{Sm}(\mathrm{III})$ and Y(III) complexes of enalapril maleate drug. In vitro antimicrobial assessment studies, J. Mol. Struct. 1059 (2014) 208-224. 